\title{
Aproveitamento de Resíduos de Processamento de Castanha de Baru para Desenvolvimento de Gelado Comestível
}

\author{
Adriana A. Carvalho, Elaine S. P. Barbosa \& Karolline F. Siqueira
}

Nos últimos anos, a demanda crescente do setor de gelados comestíveis no mercado brasileiro provoca nas indústrias a busca de novas matérias-primas e sabores como diferencial competitivo. O presente trabalho propôs desenvolver e produzir industrialmente um gelado comestível com castanha de baru para aproveitamento do subproduto do fruto no mercado. A polpa de baru é descartada na indústria de beneficiamento, gerando um subproduto. O gelado comestível com castanha de baru resultará em um produto inovador, com propriedades nutricionais potenciais e, alto valor agregado.

Palavras chave: cerrado; castanha; sorvete.

In recent years, the growing demand of ices sector in the Brazilian market causes the industry to search for new raw materials and flavors as a competitive advantage. This paper proposed to develop and industrially produce an edible ice cream with baru nuts for use by product of the fruit in the market, such as analysis of the pulp. The pulp of baru is discarded in the processing industry, generating a byproduct. Edible ice cream with baru nuts will result in an innovative product with potential nutritional properties and high added value.

Keywords: baru; chestnut; ice cream. 


\section{Introdução}

O cerrado é um dos biomas mais ricos do Brasil, possuindo diversas espécies, as quais estão sendo estudadas quanto à sua composição química, valor nutritivo e conservação ${ }^{1}$. Devido à crescente necessidade de valorização e preservação das espécies nativas, aliada à necessidade de novas fontes alternativas de nutrientes a custos acessíveis, maiores esforços têm sido feitos para estudar o potencial de muitas espécies do cerrado ${ }^{2}$.

As espécies de plantas nativas do cerrado têm-se destacado por apresentar potencial nutritivo com forte apelo sensorial e econômico, constituindo matériaprima disponível para formulação de novos produtos alimentícios ${ }^{3}$. Das espécies nativas do cerrado, o baru (Dipteryx Alata vog.) destaca-se pela amplitude de ocorrência e por convivência pacífica com o modelo de exploração praticado pelas populações rurais, em que as plantas são preservadas na abertura de pastos ${ }^{4}$. Possui diversos nomes populares, tais como: fruta-demacaco, castanha-de-burro, cumaru, cumbaru, barujo, castanha-de-ferro, coco-feijão, cumaru-da-folha-grande, cumarurana, cumaru-verdadeiro, cumaru-roxo, cumbary, emburena-brava, meriparajé, e pau-cumaru ${ }^{5}$. O baru é constituído por uma casca fina e escura de coloração marrom, polpa com sabor adocicado e adstringente, a qual abriga uma amêndoa dura e comestível.

A castanha do baru, que representa $5 \%$ do rendimento em relação ao fruto inteiro, possui valor de mercado considerável; a polpa, no entanto, ainda é pouco utilizada na alimentação humana. Considerando que a polpa possa ser usada para outras finalidades, o percentual de rendimento aproveitável do fruto aumenta para mais de $50 \%{ }^{6}$. Devido às suas características químicas, existe interesse tecnológico na casca e polpa do baru, composta principalmente por amido, fibra insolúvel e açúcares, e rica em vitaminas e sais minerais, como o potássio, cobre, ferro, cálcio, fósforo e magnésio. A polpa do fruto imaturo contém elevados teores de taninos, que diminuem com a maturação do fruto, tornando o consumo dos frutos caídos no chão mais adequado. $\mathrm{O}$ uso de subprodutos agroindustriais para o incremento de produtos alimentícios garante o enriquecimento nutricional com baixo custo, além da importante tarefa do reaproveitamento destes subprodutos ${ }^{6}$.
A flora do cerrado é desprezada pela maioria da população, que tende a considerá-la desprovida de utilidade. É importante lembrar que as frutas do cerrado podem funcionar como fontes alternativas de alimentos compondo cardápios regionais 7 . A conscientização da população do cerrado, quanto ao seu potencial de frutos nativos, pode contribuir de forma benéfica ao combate de suas deficiências nutricionais ${ }^{8}$.

A possibilidade de conservação dos recursos naturais, associada ao aproveitamento de produtos ou subprodutos provenientes do cerrado justifica a investigação de seu potencial para a formulação de produtos. Desta forma, a proposta deste trabalho foi avaliar a potencialidade da casca e polpa do baru, sendo este último como ingrediente no desenvolvimento de gelado comestível.

\section{Materiais e Métodos}

\section{ANÁLISE CENTESIMAL DA POLPA DE BARU}

O experimento foi realizado com duas repetições, e as análises foram realizadas em triplicata, com exceção da análise de fibra, que foi realizada com quatro replicatas.

O baru (Dipteryx alata $V$.) foi obtido na região Centro-Oeste, na comunidade "Promessa de Futuro", localizada no município de Pirinópolis, Goiás. Os frutos foram adquiridos de 10 barueiros diferentes, sendo 115 frutos de cada árvore, colhidos quando começaram a cair do barueiro, o que indicou o ponto ideal de colheita dos frutos ${ }^{9}$. Em seguida, foram misturados e homogeneizados.

Optou-se por colher apenas os frutos que caíram no momento da colheita para obtenção de graus de maturação parecidos para todos os frutos. Realizada a amostragem durante a colheita dos frutos, esses foram higienizados seguindo as etapas: limpeza em água corrente e depois sanitização com hipoclorito de sódio $2,5 \%$, a 200 ppm por 15 minutos $^{10}$.

A despolpa dos frutos ocorreu nos dias das análises e foi realizada de forma manual, com auxílio de facas de mesa, retirando-se primeiramente as cascas, que foram descartadas.

A amostra foi dividida em sete caixas plásticas, previamente higienizadas. As caixas foram armazenadas em uma sala localizada no laboratório de Dietética, na Faculdade de Nutrição da Universidade Federal de Goiás, a temperatura ambiente, com ventilação, ao abrigo do Sol e devidamente limpa. 
Fez-sr a composição centesimal das polpas das amostras três dias após a colheita dos frutos e também ao final de quatro meses. As análises realizadas foram: teor de proteínas e cinzas ${ }^{11}$, fibras ${ }^{12}$, lipídios ${ }^{13}$ e teor de umidade ${ }^{14}$. O teor de carboidratos foi determinado por diferença, subtraindo-se de 100 os teores de proteínas, lipídios, cinzas, umidade e fibras.

\section{VIDA DE PRATELEIRA DO SORVETE}

As amostras foram preparadas um uma indústria de gelados comestíveis, localizada na região metropolitana de Goiânia - Goiás. As amostras foram acondicionadas em embalagens rígidas e transparentes, contendo $300 \mathrm{~g}$, com informação referente à data de fabricação devidamente identificadas. Estocou-se o produto em freezer com temperatura nominal de $-18^{\circ} \mathrm{C}$ durante 180 dias. As amostras foram avaliadas antes e mensalmente durante a estocagem, sendo amostrada uma unidade a cada avaliação, identificadas conforme apresentado na Tabela 1 .

Tabela 1. Identificação das amostras para análise de vida de prateleira.

\begin{tabular}{|c|c|c|}
\hline \multirow{2}{*}{$\begin{array}{c}\text { Tempo de } \\
\text { estocagem (dias) }\end{array}$} & $\begin{array}{c}|c| \\
\text { Sorvete de baru } \\
\text { com Praliné }\end{array}$ & $\begin{array}{c}\text { Sorvete de Baru } \\
\text { com Castanha de } \\
\text { baru torrada }\end{array}$ \\
\hline 0 & SP 1 & ST 1 \\
\hline 30 & SP 2 & ST 2 \\
\hline 60 & SP 3 & ST 3 \\
\hline 90 & SP 4 & ST 4 \\
\hline 120 & SP 5 & ST 5 \\
\hline 150 & SP 6 & ST 6 \\
\hline 180 & SP 7 & ST 7 \\
\hline
\end{tabular}

\section{AVALIAÇÃO SENSORIAL}

Os testes sensoriais foram realizados no laboratório de Análise Sensorial. Para avaliação de aparência, aroma, textura e sabor foram utilizados iluminação natural. Os horários de testes foram estabelecidos, de acordo com a disponibilidade dos provadores.

Visando identificar as alterações durante a estocagem em relação aos atributos do produto preparado, foi conduzida avaliação sensorial consensual por equipe de seis julgadores, selecionados quanto à acuidade sensorial, conforme descrito ${ }^{15}$, com descrição das características detectadas.

A ficha de avaliação continha uma escala não estruturada para cada termo descritivo levantado. A escala era composta de uma linha de $10 \mathrm{~cm}$, tendo expressões quantitativas (pontos âncora) nas extremidades esquerda (equivalente ao ponto um) e direita (equivalente ao ponto dez) com os termos: "pouco" / "fraco" / "pouca" e ""muito" / "forte" / "muita", respectivamente. Os provadores por meio de um traço vertical na escala escolhiam a melhor posição que refletisse a sua avaliação para cada termo descritivo. Os valores eram obtidos, medindo-se a distância entre os pontos-âncoras da extremidade esquerda e o traço vertical feito pelo provador, com auxílio de uma régua ${ }^{15}$.

\section{Resultados e Discussões}

\section{VIDA DE PRATELEIRA DA POLPA DE BARU.}

A avaliação centesimal da polpa do baru foi realizada com 120 dias de armazenamento, pois este foi o tempo máximo que a polpa permaneceu íntegra. A partir daí, nas mesmas condições iniciais de estocagem, já se iniciou um processo de degradação da fruta (polpa), com aparecimento de bolores e leveduras. A Tabela 2 apresenta a composição centesimal aproximada da polpa de baru, recém-colhido e com 120 dias de armazenamento.

Tabela 2 - Composição centesimal aproximada (g.100g-1) da polpa de baru em diferentes tempos de armazenamento (3 e 120 dias).

\begin{tabular}{|c|c|c|}
\hline Componentea & Polpa com 3 dias & Polpa com 120 dias \\
\hline Umidade & $12,09 \pm 0,57^{*}$ & $22,47 \pm 1,04$ \\
\hline Proteínas & $3,68 \pm 0,62$ & $3,37 \pm 1,21$ \\
\hline Lipídios totais & $3,27 \pm 0,13^{*}$ & $1,76 \pm 0,42$ \\
\hline $\begin{array}{c}\text { Fibra alimentar } \\
\text { total }\end{array}$ & $19,10 \pm 0,20^{*}$ & $27,00 \pm 0,00$ \\
\hline Cinzas & $3,82 \pm 0,25^{*}$ & $2,77 \pm 0,35$ \\
\hline Carboidratosb & 58,04 & 42,63 \\
\hline
\end{tabular}

${ }^{a}$ Valores constituem média \pm desvio-padrão de duas repetições com três replicatas cada, exceto para fibra alimentar total (quatro replicatas); ${ }^{\text {b }}$ Calculado por diferença, subtraindo-se de 100 os valores obtidos para umidade, proteínas, lipídios, fibra alimentar total e cinzas; "Diferença significativa pelo teste t de Student entre os tempos de armazenamento $(\mathrm{P}<0,05)$. 
Comparando-se os valores encontrados na literatura, verifica-se que há uma divergência entre os valores de alguns componentes encontrados na polpa de baru, mas, de forma geral, a polpa deste fruto apresenta: 3,5\% a $10,13 \%$ de proteína, 3,27 a $4,13 \%$ de lipídios, 1,79 a $2,99 \%$ de cinzas. Quanto ao teor de fibras, a polpa do baru é considerada um alimento rico em fibra, apresentando por volta de $19 \%$. A fibra insolúvel predomina tanto na polpa como na amêndoa, mas principalmente, na polpa $^{2,16,17,18,19,20,21}$.

Pelos valores observados em outros estudos, podese verificar que os valores encontrados neste trabalho ficaram dentro das faixas já encontradas, exceto para carboidratos, que apresentou um valor 3 vezes maior que o relatado por Takemoto et al. $(2001)^{17}$, que relata que os carboidratos totais representam um valor em torno de 15,8 $\%$ da polpa do baru. Segundo Vallilo, Tavares e Aueds $(1990)^{20}$ e Almeida et al. (1991) ${ }^{19}$, o valor energético da polpa está em torno de $300 \mathrm{kcal} .100 \mathrm{~g}$-1, enquanto os encontrados neste estudo variaram entre 276,31 e 199,84 kcal .100 $\mathrm{g}^{-1}$.

Comparando-se as composições centesimais, podese observar que a proteína foi o único componente a se manter significativamente igual $(\mathrm{P}>0,05)$ ao longo de 120 dias de estocagem. $\mathrm{O}$ aumento no valor da umidade se deve, provavelmente, às condições ambientais de umidade que foram modificando ao longo do experimento, afetando significativamente a quantidade de água livre na polpa do fruto e comprovando mais uma vez que este parâmetro está relacionado à estabilidade de alimento $^{23}$, uma vez que a partir de 120 dias, quando a umidade ambiental estava alta, o fruto começou a apresentar o crescimento de fungos. O teor de cinzas diminuiu por possuir relação inversa com a umidade.

A diminuição dos carboidratos ao longo do período de estocagem pode ser explicado também pelo aumento da umidade, pois com tal fato, os carboidratos se diluem na composição. Ainda pode estar associado aumento da quantidade de fibras. Possivelmente, o aumento na quantidade de fibras, do primeiro para o sexto tempo de estoque, deve-se pela ocorrência da transformação dos amidos presentes na polpa em amido resistente, que foram detectados como fibras insolúveis ${ }^{24,25,26}$.
Pôde-se observar que, durante toda a etapa de estocagem, os componentes químicos de um alimento vão se perdendo e, ou se transformando em outras substâncias que determinam a vida útil desse. A menor ou maior vida de prateleira de um fruto depende, entre outros fatores, da maneira como é estocado, do ambiente em que é mantido, uma vez que a mudança dos constituintes naturais é inevitável e pode ocorrer de forma acelerada quando as condições são adversas.

\section{VIDA DE PRATELEIRA DO SORVETE COM PRALINÉ}

Os Perfis Sensoriais das amostras analisadas estão representados na Figura 1, em que as características sensoriais iniciais $(T=0)$ do produto encontram-se descritas a seguir:

- Aparência: massa gelada e cremosa de coloração marrom claro, com pequenos pedaços de polpa de baru de coloração caramelo, partículas escuras e pontos marrom avermelhados, observando-se ao redor das partículas calda de coloração caramelo;

- Aroma: aroma global pouco intenso lembrando a ameixa preta seca - em escala de 1 (fraco) a 10 (forte), as intensidades correspondem a nota 5 para o aroma global e nota 5 para ameixa preta seca. Livre de odores estranhos;

- Textura: pouco cremoso, levemente arenoso e de rápido derretimento, com presença de partículas firmes;

- Sabor: sabor global suave, frutal característico de baru lembrando a ameixa preta seca, doce, levemente ácido e levemente lácteo, com presença de calda com intensidade moderada de sabor caramelo - em escala de 1 (fraco) a 10 (forte), as intensidades correspondem a nota 6,5 para o sabor global, nota 7 para o sabor frutal, nota 7 para doce, nota 4 para ácido, nota 4 para o sabor lácteo e nota 5 para o sabor caramelo da calda. Livre de sabores estranhos. 


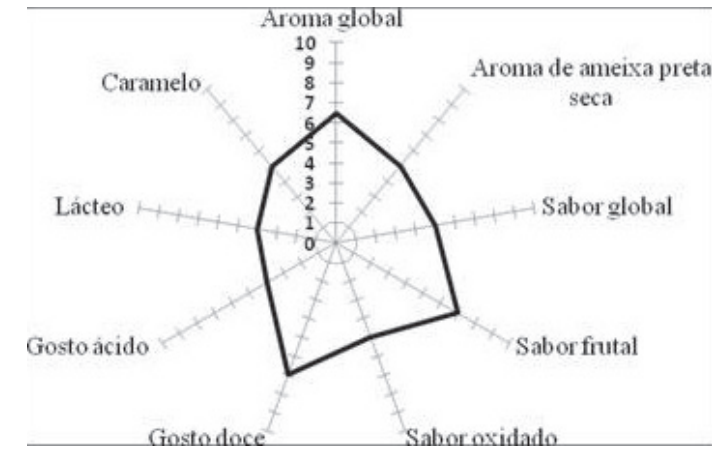

Figura 1. Perfil de aroma e sabor obtido a partir da avaliação consensual dos julgadores para o sorvete de baru com pralinés antes e após 180 dias de estocagem sob congelamento.

As amostras armazenadas nos tempos 30, 60, 90 e 120 dias de estocagem mantiveram as características iniciais do produto. Aos 150 dias de estocagem verificou-se que alguns SP apresentam sabor oxidado, com intensidade moderada - nota 5 em escala de 1 (fraco) a 10 (forte). Aos 180 dias, as características observadas aos 150 dias se mantiveram, ficando o produto com as características a seguir:

- Aparência: massa gelada e cremosa de coloração marrom claro, com pequenos pedaços de praliné de coloração caramelo, partículas escuras e pontos marrom avermelhados, observando-se ao redor dos pralinés calda de coloração caramelo;

- Aroma: aroma global pouco intenso lembrando a ameixa preta seca - em escala de 1 (fraco) a 10 (forte), as intensidades correspondem a nota 5 para o aroma global e nota 5 para ameixa preta seca. Livre de odores estranhos;

- Textura: pouco cremoso, levemente arenoso e de rápido derretimento, com presença de partículas firmes;

- Sabor: sabor global suave, frutal característico de baru lembrando a ameixa preta seca, doce, levemente ácido e levemente lácteo, com presença de calda com intensidade moderada de sabor caramelo - em escala de 1 (fraco) a 10 (forte), as intensidades correspondem a nota 6,5 para o sabor global, nota 7 para o sabor frutal, nota 7 para doce, nota 4 para ácido, nota 4 para o sabor lácteo e nota 5 para o sabor caramelo da calda. Presença de sabor oxidado em alguns pedaços de praliné - nota 5 em escala de 1 (fraco) a 10 (forte).
Assim, verifica-se que, ao longo da estocagem, a principal alteração do produto refere-se ao desenvolvimento de sabor oxidado nos pralinés presentes no sorvete a partir de 150 dias de estocagem. A Figura 1 ilustra o aroma e sabor do produto, considerando as notas atribuídas consensualmente pelos julgadores ao produto no início e após 180 dias de estocagem.

\section{SORVETE DE BARU COM CASTANHA DE BARU TORRADA}

As características sensoriais iniciais do produto (tempo inicial) encontram-se descritas a seguir.

- Aparência: massa gelada e cremosa de coloração marrom claro, com pequenos pedaços de castanha de coloração caramelo, partículas escuras e pontos marrom avermelhados;

- Aroma: aroma global pouco intenso lembrando a castanha torrada e ameixa preta seca - em escala de 1 (fraco) a 10 (forte), as intensidades correspondem a nota 5 para o aroma global e nota 4 para castanha torrada e ameixa preta seca. Livre de odores estranhos;

- Textura: pouco cremoso e de rápido derretimento, com presença de partículas firmes;

- Sabor: sabor global suave, frutal característico de baru lembrando a ameixa preta seca, doce, levemente ácido e levemente lácteo, com sabor intenso de castanha torrada - em escala de 1 (fraco) a 10 (forte), as intensidades correspondem a nota 6,5 para o sabor global, nota 6,5 para o sabor frutal, nota 7 para doce, nota 4 para ácido, nota 4 para o sabor lácteo e nota 7 para o sabor de castanha torrada. Livre de sabores estranhos.

Até completar 30, 60, 90 e 120 dias de estocagem, as características iniciais do produto mantiveram-se e estáveis.

Aos 150 dias de estocagem, verificou-se que algumas castanhas apresentam sabor oxidado, com intensidade moderada - nota 5 em escala de 1 (fraco) a 10 (forte). Aos 180 dias de estocagem as características observadas aos 150 dias se mantiveram, ficando o produto com as características a seguir:

- Aparência: massa gelada e cremosa de coloração marrom claro, com pequenos pedaços de castanha de coloração caramelo, partículas escuras e pontos marrom avermelhados; 
- Aroma: aroma global pouco intenso lembrando a castanha torrada e ameixa preta seca - em escala de 1 (fraco) a 10 (forte), as intensidades correspondem a nota 5 para o aroma global e nota 4 para castanha torrada e ameixa preta seca. Livre de odores estranhos;

- Textura: pouco cremoso e de rápido derretimento, com presença de partículas firmes;

- Sabor: sabor global suave, frutal característico de baru lembrando a ameixa preta seca, doce, levemente ácido e levemente lácteo, com sabor intenso de castanha torrada - em escala de 1 (fraco) a 10 (forte), as intensidades correspondem a nota 6,5 para o sabor global, nota 6,5 para o sabor frutal, nota 7 para doce, nota 4 para ácido, nota 4 para o sabor lácteo e nota 7 para o sabor de castanha torrada. Presença de sabor oxidado em alguns pedaços de castanha torrada - nota 5 em escala de 1 (fraco) a 10 (forte).

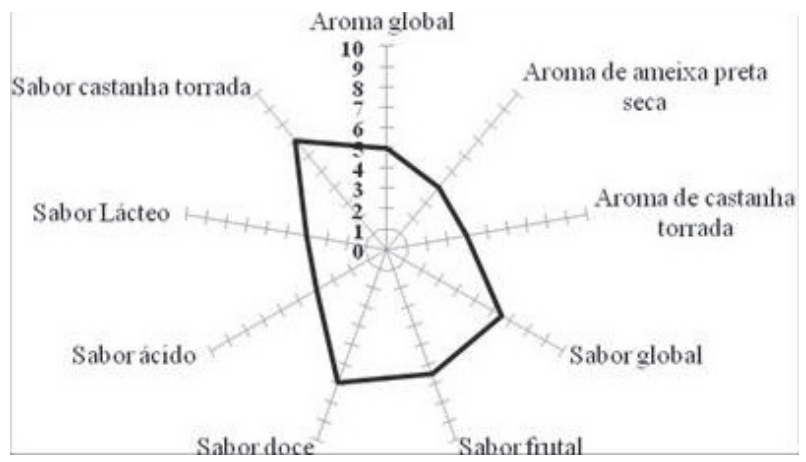

Figura 2. Perfil de aroma e sabor obtido a partir da avaliação consensual dos julgadores para o Sorvete de Baru com Castanha de Baru Torrada antes e após 180 dias de estocagem sob congelamento.

Assim, verifica-se que, ao longo da estocagem ,a principal alteração do produto refere-se ao desenvolvimento de sabor oxidado nas castanhas torradas presentes no sorvete a partir de 150 dias de estocagem. A Figura 2 ilustra o aroma e sabor do produto, considerando as notas atribuídas consensualmente pelos julgadores ao produto no início e após 180 dias de estocagem.

\section{Conclusão}

Os resultados obtidos neste trabalho permitiram ampliar as possibilidades de aplicação de polpa de baru como ingrediente na indústria alimentícia, uma vez que, as análises químicas ao final de três e 120 dias mostraram que a polpa de baru apresenta, em geral, teores de nutrientes favoráveis à saúde humana, aumentando o aproveitamento do fruto, que atualmente se restringe ao consumo da amêndoa.

Ao longo da estocagem sob congelamento, a única alteração dos dois produtos relacionou-se ao desenvolvimento de sabor oxidado nos Pralinés e nas Castanhas de Baru Torradas, sendo estas alterações percebidas a partir de 150 dias de estocagem com intensidade moderada, que se manteve até o final de estocagem aos 180 dias. A definição do prazo de validade deverá levar em conta o risco que a empresa está disposta a assumir em relação à possível percepção de alterações sensoriais no produto pelos consumidores.

\section{Referências}

1. Rigonato, V. D.; Almeida, M. G.. A singularidade do cerrado: a interrelação das populações tradicionais com as fitofisionomias. VIII EREGEO - Encontro Regional de Geografia, Cidade de Goiás, 2003.

2. Togashi, M.; Sgarbieri, V. C.. Caracterização química parcial do fruto do baru. Ciência e Tecnologia de Alimentos, Campinas, v. 14, n. 1, p. 85-95, 1994.

3. Hiane, A. P. et al. Composição centesimal e perfil de ácidos graxos de alguns frutos nativos do Estado de Mato Grosso do sul. Boletim do Centro de Pesquisas e Processamento de Alimentos, v. 10, n. 1, p. 35-42, 1992.

4. Corrêas, G. C. et al. Caracterização física de frutos de baru (Dipteryx alata Vog.) em três populações nos cerrados do Estado de Goiás. Pesquisa Agropecuária Tropical, v. 30, n. 2, p. $5-11,2000$.

5. Botezelli, L.; Davide, A. C; Malavasi, M. M. Características dos frutos e sementes de quatro procedências de Dipteryx alata vogel (baru). Cerne, v. 6, n. 1, p. 9-18, 2000.

6. Ribeiro, J. F. et al. Baru (Dipteryx alata vogel) Jaboticabal: Funep, 2000. 41 p.

7. Avido, M. F.; Derreira, L. T.. Frutos dos cerrados: preservação gera muitos frutos. 2005. Disponível Em: < http://www. biotecnologia.com.br/bio15/frutos.pdf > . Acesso em; 22 mar 2015.

8. Pinto, P. C. R. Consumo alimentar de frutos do Cerrado, fontes de Vitamina A, por moradoras de comunidades das cidades satélites do Distrito Federal Sano, S. M.; Ribeiro, J. F.; Brito, M. A. Baru: biologia e uso. Planaltina: EMBRAPA Cerrado, 2004. 52 p. 
9. Sano, S. M.; Ribeiro, J. F.; Brito, M. A. Baru: biologia e uso. Planaltina: EMBRAPA Cerrado, 2004. 52 p.

10. Silva, J. A. Tópicos da Tecnologia de Alimentos. São Paulo: Livraria Varela, 2000. 227 p.

11. Association Of Official Agricutural Chemists - AOAC. Official methods of analysis. Washington D. C., 1984, 1141 p.

12. Association Of Official Agricutural Chemists - AOAC. Official methods of analysis. $15^{\mathrm{a}}$ ed. Washington D. C., 1990, p. 11051106.

13. Bligh, E. G.; Dyer, W. J. A rapid method of total lipid extraction and purification. Can. J. Biochem. Physiol., v. 37, p. 911-917, 1959.

14. Instituto Adolfo Lutz - IAL. Métodos químicos e físicos para análise de alimentos. $3^{\mathrm{a}}$ ed. São Paulo: O Instituto, 1985. 533 p.

15. Chaves, J. B. P.; Sproesser, R. L. Práticas de laboratório de análise sensorial de alimentos e bebidas. Viçosa, MG: Universidade Federal de Viçosa, 2002. 81 p.

16. Rocha, L. S. Caracterização Físico-química, microbiológica e sensorial de pães de forma elaborados com subprodutos de baru (Dipteryx alata Vog.). 2007. 52 f. Dissertação (Mestrado em Ciência e Tecnologia de Alimentos) - Universidade Federal de Goiás, Goiânia, Goiás, 2007.

17. Takemoto, E.; Okada, I. A.; Garbelotti, M. L.; Tavares, M.; Aued-Pimentel, S. Composição química da semente e do óleo de baru (Dipteryx alata Vog.) nativo do município de Pirenópolis, Estado de Goiás. Revista do Instituto Adolfo Lutz, São Paulo, v. 60, n. 2, p. 113-117, 2001.

18. Togashi, M.; Sgarbieri, V. C. Avaliação nutricional da proteína e do óleo de sementes de baru (Dypterix alata Vog). Ciência e Tecnologia de Alimentos, Campinas, v. 15, n. 1, p. 66-69, 1995.

19. Almeida, S. P.; Silva, J. A.; Ribeiro, J. F. Aproveitamento alimentar de espécies nativas dos cerrados: araticum, baru, cagaita e jatobá. $2^{\mathrm{a}}$ ed. Planaltina: EMBRAPA - CPAC, 1991

20. Vallilo, M.; Tavares, I.; Aueds, S. Composição da polpa e da semente do fruto de cambaru (Dypterix alata Vog). Caracterização do óleo da semente. Revista Instituto Florestal, Piracicaba, v. 2, p. 115-1255, 1990.

21. Filgueiras, T. S.; Silva, E. Estudo preliminar do baru (Leg. Faboideae). Brasil Florestal, v. 6, p. 33-39, 1975.

22. Almeida, S. P.; Proença, C. E. B.; Sano, S. M.; Ribeiro, J. F. Cerrado: espécies vegetais úteis. $2^{\mathrm{a}}$ ed. Planaltina: EMBRAPA - CPAC, 1998.

23. Cecchi, H. M. Fundamentos teóricos e práticos em análise de alimentos. $3^{\text {a }}$ ed. Campinas: UNICAMP, 2005. 207p.

24. Institute of medicine of the national academies. Dietary Reference Intaker. Washington: The National Academies Press, 2005. $1331 \mathrm{p}$.
25. Lobo, A. R.; Silva, G. M. L. Amido resistente e suas propriedades físico-químicas. Revista Nutrição, Campinas, v. 16, n. 2, p. 219-226, 2003.

26. Kritchevsky, D.; Bonfield, C.; Anderson, J. W. Dietary Fiber. Washington, Plenum Press, 1988. 499p.

\section{Adriana A. Carvalho, Elaine S. P. Barbosa* \& Karolline F. Siqueira}

Instituto SENAI de Tecnologia em Alimentos e Bebidas,-- Rua Professor Lázaro Costa nº 348, Vila Canaã, CEP: 74415-420, Goiânia, Goiás, Brasil.

*E-mail: elaine.spb@gmail.com 